\title{
New trephine for keratoplasty with interchangeable blade
}

\author{
H. SORIANO AND A. GANOSSA \\ Clinique universitaire d'Ophtalmologie, Genève (Director: Prof. F. Babel)
}

Instruments available for corneal transplantations require to be made with infinite care, and their price is consequently high. The cutting-edge of the instrument, which is extremely fine, needs to be sharpened frequently and the instruments are very fragile.

Franceschetti and Canossa (1957) described a trephine for the removal of the whole cornea, with a cutting-edge made from two fragments of a razor blade.

This prototype has prompted us to devise a trephine fitted with a new type of razor blade which is interchangeable and flexible, four-tenths of a millimetre $(0.4 \mathrm{~mm}$.) thick, easily purchased, and cheap. It has an internal piston, which can be regulated by means of a micrometer screw, and a reference drum, each mark of which corresponds to one-tenth of a millimetre ( $0 \cdot 1 \mathrm{~mm}$.) (Figure). This makes it possible to estimate with precision the depth of the cut, especially in the case of lamellar transplantations. This trephine is made of stainless metal and can be sterilized without difficulty.

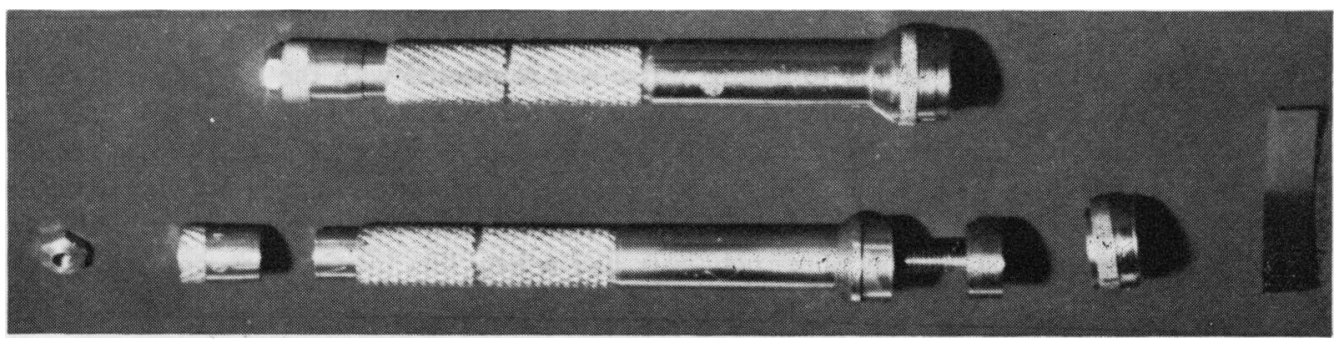

FIGURE Trephine for keratoplasty with interchangeable blade

\section{References}

FRANCESCHETtT, A., and CANOSSA, A. (1957) Trans. ophthal. Soc. U.K., 77, 109 